\title{
ASPECTOS MORFO-ANATÔMICOS DE TRÊS ESPÉCIES DE DROSERA, DURANTE O DESENVOLVIMENTO PÓS-SEMINAL
}

\author{
Vitor Fernandes Oliveira de Miranda' \\ Maria das Graças Sajo ${ }^{2}$
}

Recebido em 10/09/1999. Aceito em 14/03/2000

\begin{abstract}
RESUMO - (Aspectos morfo-anatômicos de três espécies de Drosera, durante o desenvolvimento pós-seminal). Durante o processo de germinação, as sementes das três espécies (Drosera spathulata Labill., D. intermedia Dreves \& Hayne e D. burmanni Vahl) rompem-se por meio de um opérculo e as plântulas desenvolvem pêlos unicelulares ancoradouros antes do estabelecimento da raiz primária. A porção apical dos cotilédones permanece no interior dos envoltórios das sementes e possui função haustorial. Diferentes tricomas são constatados nas folhas e cotilédones das plântulas, inclusive na superfície das emergências. Alguns aspectos morfo-anatômicos das folhas também são apresentados.
\end{abstract}

Palavras-chave - desenvolvimento pós-seminal, Drosera, anatomia foliar

\begin{abstract}
Morphology and anatomy of the post-seminal development of three species of Drosera). During germination, the seeds of the three species (Drosera spathulata Labill., Drosera intermedia Dreves \& Hayne e $D$. burmanni Vahl) rupture by way of an operculum with the seedlings forming anchorage hairs before the development of primary roots. The cotyledon apexes remain inside the seed integuments and have a haustorial function. Different trichomes are found on the leaves and cotyledons of seedlings, and on emergence surfaces. Some anatomical aspects of leaves are also presented.
\end{abstract}

Key words - post-seminal development, Drosera, leaf anatomy

\section{Introdução}

A família Droseraceae está representada por aproximadamente 100 espécies, reunidas em quatro gêneros, sendo Dionaea Ellis, Aldrovanda L. e Drosophyllum Link monotípicos, enquanto Drosera $\mathrm{L}$. compreende as demais espécies da família. Geralmente são plantas herbáceas, perenes, acaules, com folhas dispostas em roseta e, com exceção de Drosophyllum, não possuem câmbio funcional (Cronquist 1981).

As folhas de Drosera são cobertas por emergências que produzem a mucilagem utilizada para a captura de insetos. Apesar de determinados autores definirem essas estruturas como tricomas glandulares (Fahn 1978; Raven

Bolsista de Iniciação Científica, FAPESP

2 Departamento de Botânica, IBUNESP, C. Postal 199, CEP 13506-900, Rio Claro, SP, Brasil. Bolsa de Produtividade em Pesquisa, $\mathrm{CNPq}$ 
et al. 1996), ou mesmo como tentáculos (Darwin 1896; Fernandes 1941; Lloyd 1942; Cutter 1986; Juniper et al. 1989; Seine \& Barthlott 1993), é mais correto chamá-las emergências pois, de acordo com Theobald et al. (1979), as emergências distinguem-se dos tricomas por serem formadas por tecidos epidérmico e subepidérmicos. Segundo Cutter (1986), as emergências apresentam um pedúnculo multicelular e uma cabeça com três a quatro camadas de células recobertas por cutícula, perfurada na região das células glandulares. No interior do pedúnculo existe um feixe de traqueídes envolvido por uma camada endodérmica, com células portadoras de estrias de Caspary.

Para o Brasil é referida apenas a ocorrência do gênero Drosera L., com 11 espécies catalogadas por Barroso et al. (1978). Dentre os trabalhos taxonômicos, que tratam das Drosera brasileiras, destacam-se os de Saint-Hilaire (1824 a, b), que descreveu a maioria das espécies, e os de Diels (1906), que fez revisão mundial da família. Posteriormente, as Droseraceae brasileiras foram descritas em floras regionais por Santos (1968, 1980), Andrade-Lima \& Lima (1968) e por Silva (1991, 1995).

Representantes do gênero Drosera são encontrados em regiões temperadas e tropicais (Cronquist 1981), onde muitas vezes ocorrem de forma endêmica, e têm como principais centros de diversidade genética a Austrália e a Nova Zelândia. São típicos de lugares úmidos e turfosos podendo haver, de acordo com Silva (1994), espécies xerofíticas.

Poucos são os trabalhos sobre a morfoanatomia de Droseraceae. Boesewinkel (1989) descreveu o desenvolvimento de óvulos e sementes de algumas espécies da família e, mais recentemente, Seine \& Barthlott (1993) mostraram aspectos morfológicos dos tricomas e emergências desses representantes. Conran $e t$ al. (1997) fizeram interessante estudo sobre os padrões de germinação de diferentes espécies de Drosera, mostrando que determinados caracteres relacionados ao desenvolvimento pósseminal podem ser empregados em taxonomia.

Por serem plantas carnívoras, as Droseraceae, particularmente as dos gêneros Drosera e Dionaea, são requisitadas para ornamentação. No Brasil, são freqüentemente encontradas em floriculturas ou feiras e, apesar de serem exigentes em relação à iluminação e ao substrato, são facilmente cultivadas em ambiente doméstico.

$\mathrm{O}$ presente trabalho descreve as principais modificações morfo-anatômicas ocorridas durante o desenvolvimento pós-seminal de Drosera spathulata, D. intermedia e $D$. burmanni.

\section{Material e métodos}

O material foi obtido a partir de espécimes cultivados, presentes na coleção viva de plantas carnívoras da UNESP, Rio Claro. As exsicatas encontram-se depositadas no Herbário Rioclarense (HRCB), sob as seguintes especificações: Drosera intermedia Dreves \& Hayne, HRCB 28269 (Fig. 1), Drosera burmanni Vahl, HRCB 28270 (Fig. 2), e Drosera spathu-lata Labill., HRCB 28268 (Fig. 3).

As plântulas foram obtidas através da germinação de sementes em placas de Petri, sob luminosidade e temperatura ambientes.

Para os estudos morfo-anatômicos, exemplares das três espécies de Drosera, em diferentes fases de desenvolvimento pósseminal, foram fixados em FAA 50 (Johansen 1940). Procurou-se obter plântulas em estádio progressivo de desenvolvimento, utilizando-se como critério de seleção plântulas com número crescente de folhas. O material das plantas adultas foi obtido a partir de espécimes cultivados. O material foi submetido à desidratação em série etílica, incluído em historresina (Ruetze \& Schmitt 1986) e seccionado transversal e longitudinalmente em micrótomo rotativo. Os cortes foram corados 


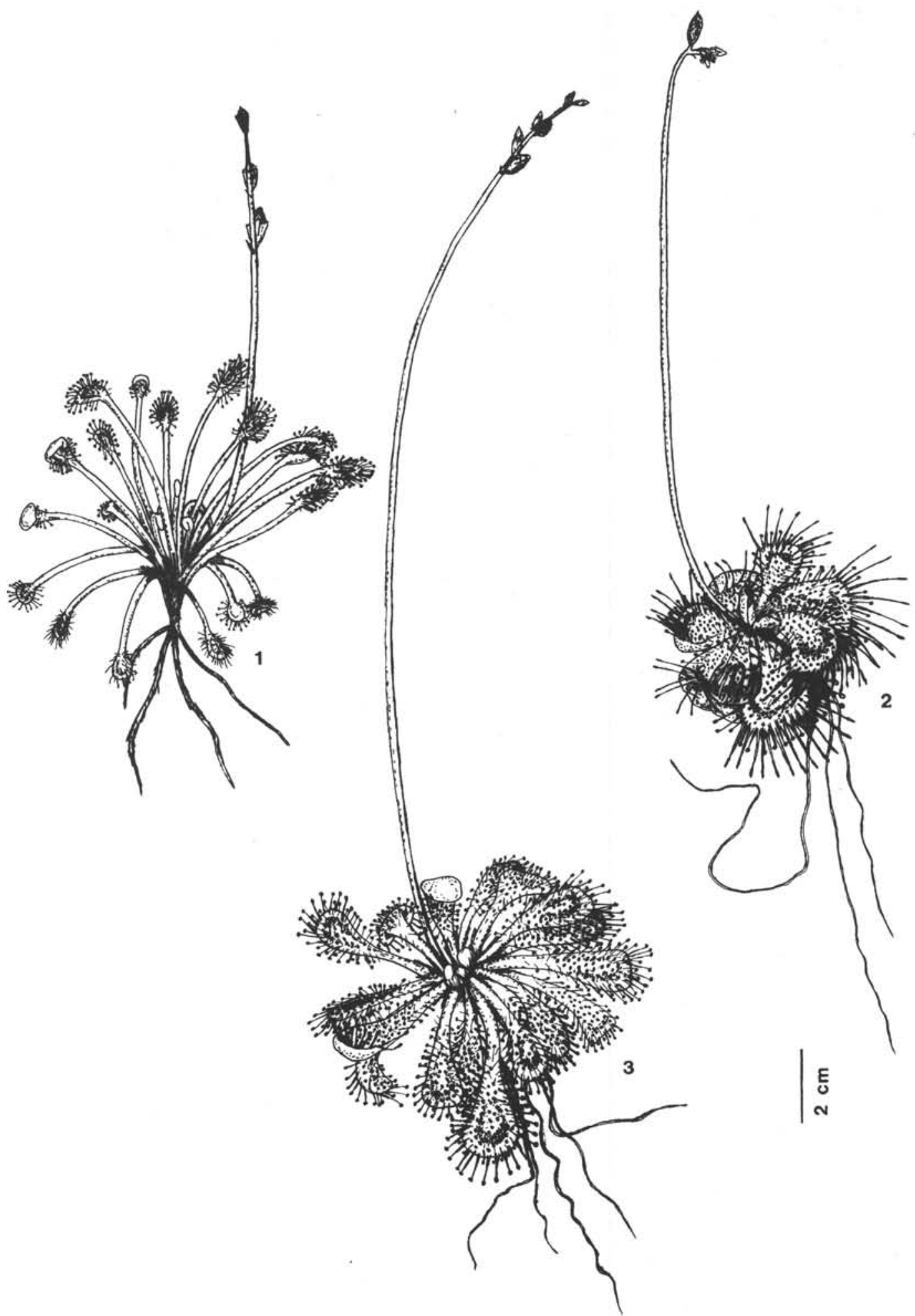

Figuras 1-3. Hábito de espécimes adultos de Drosera. 1. Drosera intermedia. 2. Drosera burmanni. 3. Drosera spathulata. 
com azul de toluidina (O'Brien et al. 1964) e a montagem final das lâminas foi feita com resina sintética. Os detalhes anatômicos foram registrados por meio de fotomicroscópio (Zeiss), e os morfológicos, em estereomicroscópio (Olympus).

\section{Resultados e discussão}

O comprimento das sementes varia entre as espécies estudadas, sendo em média de $600 \mu \mathrm{m}$ em D. spathulata (Fig. 4), $300 \mu \mathrm{m}$ em $D$. burmanni (Fig. 5) e $550 \mu \mathrm{m}$ em $D$. intermedia (Fig. 6). Boesewinkel (1989) afirma que os diferentes tamanhos das sementes de Drosera são causados unicamente pela expansão da região micropilar ou calazal. A morfologia externa das sementes também é diferente, dependendo da espécie considerada. Em $D$. spathulata, a testa é reticulada (Fig.4), em $D$. burmanni, é lisa com pequenas depressões (Fig. 5) e, em Drosera intermedia, a testa é papilosa (Fig. 6).

As três espécies de Drosera mostram seqüência de eventos semelhantes no desenvolvimento pós-seminal (Fig. 7-11). Durante a germinação, pequeno opérculo é empurrado pela raiz primária, tornando-se visível externamente. Segundo Boesewinkel (1989), em Drosera o opérculo é formado pelas extremidades do tegumento interno da semente.

A porção superior dos cotilédones permanece no interior dos tegumentos da semente, após a emergência da plântula (Fig. 8, 15). Os cotilédones são órgãos alongados, pobres em material de reserva e possuem função fotossintetizante, indicada pela presença de cloroplastos em suas células. As células da porção superior dos cotilédones, em contato com o endosperma, apresentam núcleos conspícuos, indicando atividade metabólica (Fig. 15-16); provavelmente essas células atuam na absorção de nutrientes do endosperma, rico em reservas, e fornecem suprimento para a plântula até seu completo estabelecimento. Cotilédones com função haustorial são também referidos para
Drosophyllum e Aldrovanda (Droseraceae) por Diels (1906) e para muitas monocotiledôneas (Tillich 1995). A germinação é do tipo epígea. Após a emergência, as plântulas desenvolvem pêlos epidérmicos unicelulares na base do hipocótilo (Fig. 7-10) que atingem grande comprimento e cuja função vai além da de absorção de água e nutrientes. Os pêlos apresentam paredes delgadas (Fig. 17), observando-se muitas vezes um dobramento na base, próximo à epiderme, que pode ser confundido com parede celular. Crescem em direção ao substrato e, ao atingi-lo, cessam o crescimento. Dessa forma, a plântula é ancorada e sustentada verticalmente. No ápice dos pêlos, na região de contato com o substrato, aparecem dilatações que funcionam como apressórios (Fig. 18), promovendo maior eficiência na fixação da plântula.

Sculthorpe (1967), descrevendo a germinação de plantas aquáticas, notou o desenvolvimento de pêlos radiculares longos, na base do hipocótilo. Para o autor, a presença desses pêlos compensaria a ausência de uma raiz ancoradoura e manteria a plântula estável durante o desenvolvimento da plúmula e expansão dos cotilédones. Mais recentemente, Cook (1987), em estudo sobre germinação e estabelecimento de plantas aquáticas e anfíbias, verificou, em espécies do gênero Limnocharis (Limnocharitaceae), Vallisneria (Hydrocharitaceae) e Elatine (Elatinaceae), a ocorrência de numerosos pêlos que ancoram a plântula antes que as raízes e folhas se desenvolvam. Tais pêlos, denominados "pêlos de suporte" pelos autores, parecem análogos aos encontrados nas espécies de Drosera estudadas.

Considerando que os representantes do gênero Drosera ocorrem geralmente em solos hidromórficos, os pêlos do hipocótilo devem contribuir para o estabelecimento da plântula, evitando seu transporte nos estádios iniciais de desenvolvimento, como sugerido por Sculthorpe (1967) e Cook (1987). A presença dessas estruturas pode também representar caráter 


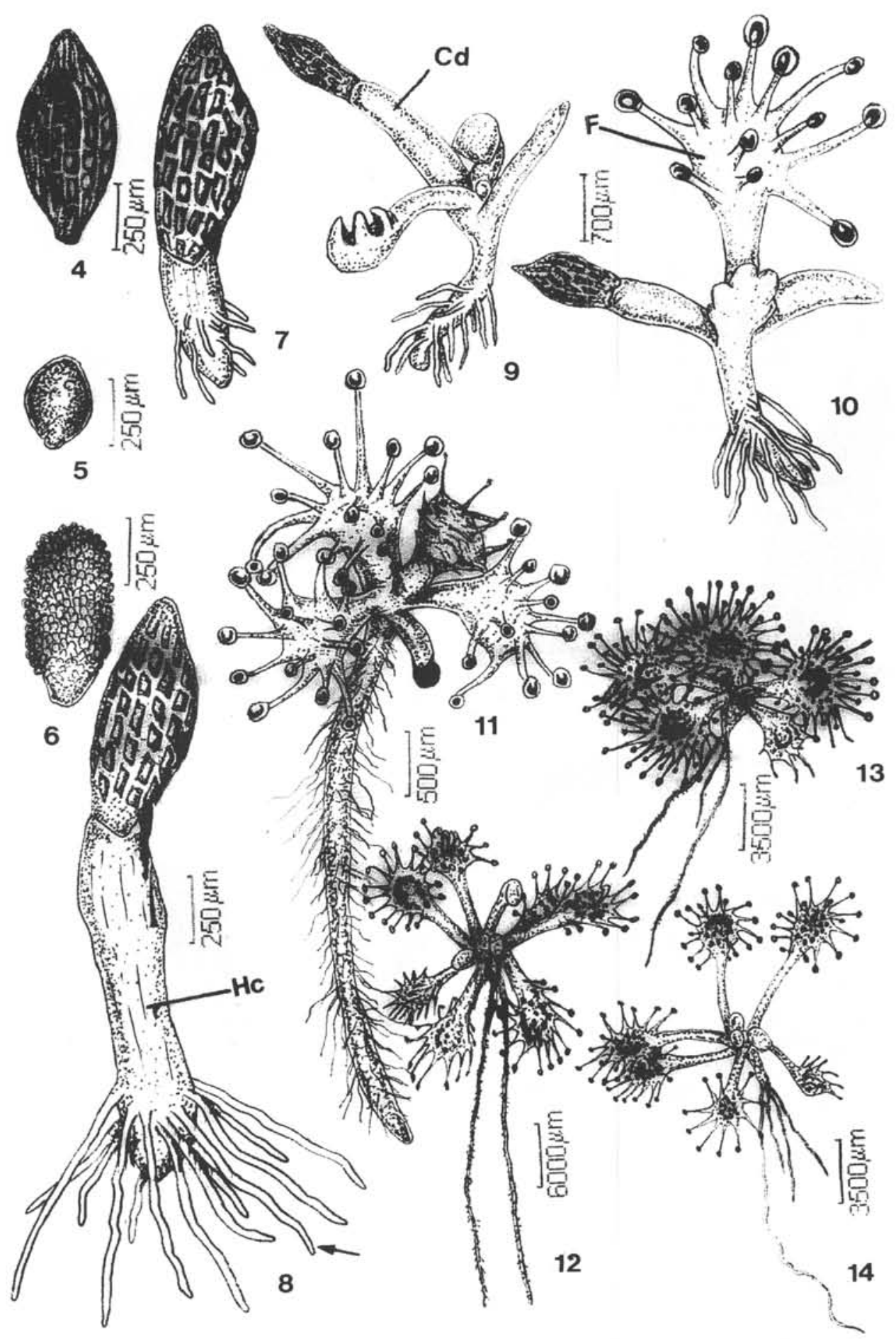

Figuras 4-6. Sementes de Drosera. Fig. 4. D. spathulata. Fig. 5. D. burmanni. Fig. 6. D. intermedia, Fig, 7-10. Diferentes estádios do desenvolvimento pós-seminal de $D$. spathulata. Fig. 11. Plântula de $D$. burmanni com 45 dias após a germinação. Fig. 12-14. Plantas jovens de D. spathulata, D. burmanni e D. intermedia, respectivamente. Cd-cotilédone; F-folha primária; Hc-hipocótilo; seta-pêlo radicular unicelular. 


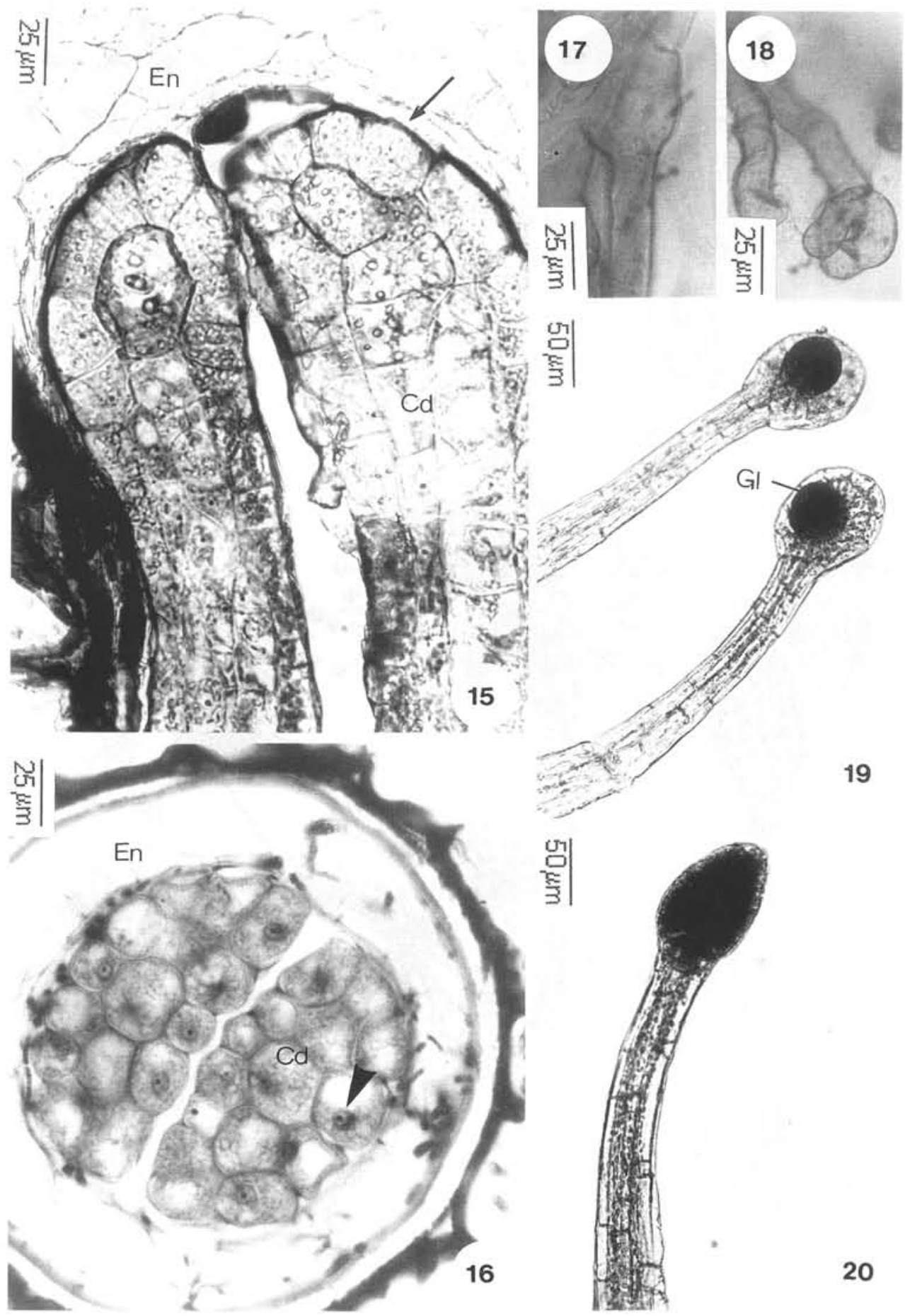

Figura 15. Corte longitudinal de plântula de $D$. intermedia mostrando a porção superior dos cotilédones retida nos envoltórios da semente e em contato com o endosperma (seta). Fig. 16. Corte transversal da porção superior dos cotilédones de plântula de D. spathulata, mostrando células com núcleos desenvolvidos (seta). Fig. 17-18. Pêlos ancoradouros presentes no hipocótilo de plântulas de D. intermedia. Fig. 19-20. D. burmanni. Fig. 19. Emergência bilateralmente simétrica. Fig. 20. Emergência radialmente simétrica. Cd-cotilédone; En-endosperma; Gl-glândula. 
plesiomorfo para o gênero, principalmente se levar-se em conta o fato de que Aldrovanda, gênero filogeneticamente relacionado a Drosera (Williams et al. 1994), é considerado primitivo e é aquático.

Quando a raiz primária se estabelece e fornece suporte à plântula, os pêlos do hipocótilo degeneram (Fig. 11). Apesar de serem estruturas temporárias e de participarem na ancoragem da plântula, pode-se supor que estejam também envolvidos na absorção de água e solutos.

Até 45 dias após a germinação, não se observa a degeneração da raiz primária, como indicado por Diels (1906). Entretanto, nesse estádio de desenvolvimento, já se observa o sistema radicular formado por inúmeras raízes adventícias (Fig. 12-14).

Embora as diferentes espécies de Drosera apresentem, quando adultas, folhas de formas e dimensões características (Fig. 1-3), nos estádios iniciais de desenvolvimento esses órgãos são semelhantes: apresentam lâminas espatuladas e pecíolos reduzidos (Fig. 10-11). Folhas espatuladas, com pecíolos inconspícuos são consideradas como formas primitivas em Drosera (Leavitt 1903, 1909). Por esse motivo, pode-se considerar que, para o gênero, a ontogenia foliar reflita a filogenia do grupo: as formas foliares, presentes nos estádios iniciais de desenvolvimento da planta, seriam semelhantes às encontradas nos ancestrais do gênero.

As primeiras e segundas folhas são desprovidas de estípulas e possuem emergências em menor número que as folhas adultas. À medida que se observam folhas mais velhas, nota-se aumento progressivo no número das emergências, tornando-se difícil estabelecer o limite entre plântula e planta em estádio juvenil, dada à similaridade entre as folhas nessas duas fases (Fig. 10-14). Desta forma, a utilização do sistema radicular poderia ser útil para a distinção entre as fases de plântula, planta jovem e planta adulta. Assim, propõe-se considerar no presente estudo como plântula os espécimes de Drosera que ainda possuem raiz primária (Fig. 9-11), planta jovem aqueles cujo sistema radicular fasciculado encontra-se em processo de formação (Fig. 12-14) e, finalmente, planta adulta os espécimes que possuem o sistema radicular fasciculado estabelecido, sem a presença da raiz primária (Fig. 1-3).

Seine \& Barthlott (1993) reconhecem nas folhas de Drosera quatro tipos básicos de emergências glandulares. Entretanto, no presente estudo, só foram reconhecidos dois tipos: emergência radialmente simétrica, com cabeça dilatada coberta por tecido secretor (Fig. 20), e emergência bilateralmente simétrica com margem distinta, cuja porção secretora encontrase na concavidade adaxial (Fig. 19). As primeiras distribuem-se na superfície adaxial das lâminas, e as segundas limitam-se às margens do órgão (Fig. 21), nas três espécies estudadas.

As folhas (tanto das plântulas, plantas jovens como das adultas) são anfiestomáticas e a epiderme em vista frontal é formada por células alongadas nas duas superfícies; os estômatos são anomocíticos (Fig. 24-29).

Em corte transversal, as folhas de indivíduos jovens das três espécies estudadas mostram epiderme uniestratificada, mesofilo homogêneo lacunoso e vários feixes vasculares colaterais (Fig. 22). De cada feixe partem cordões de traqueídes que suprem as emergências secretoras. O pecíolo, em corte transversal, apre-senta epiderme uniestratificada com estômatos em toda a superfície e parênquima lacunoso envolvendo três feixes vasculares (Fig. 23).

Nas folhas (de plântulas, plantas jovens e adultas) e cotilédones das espécies estudadas observam-se, ainda, tricomas tectores e glandulares de diferentes tipos (Fig. 30-38). Eles ocorrem nas lâminas, pecíolos e emergências glandulares, sendo que nas folhas jovens de $D$. spathulata e $D$. intermedia observam-se apenas os tricomas da Fig. 33, e nas de D. burmanni, os das Fig. 32 e 35 . Esta distribuição pode ter valor taxonômico pois $D$. burmanni pertence à seção Thelocalyx e as outras, à seção Rossolis.

Nas folhas adultas de $D$. intermedia, predominam os tricomas da Fig. 31, embora os 

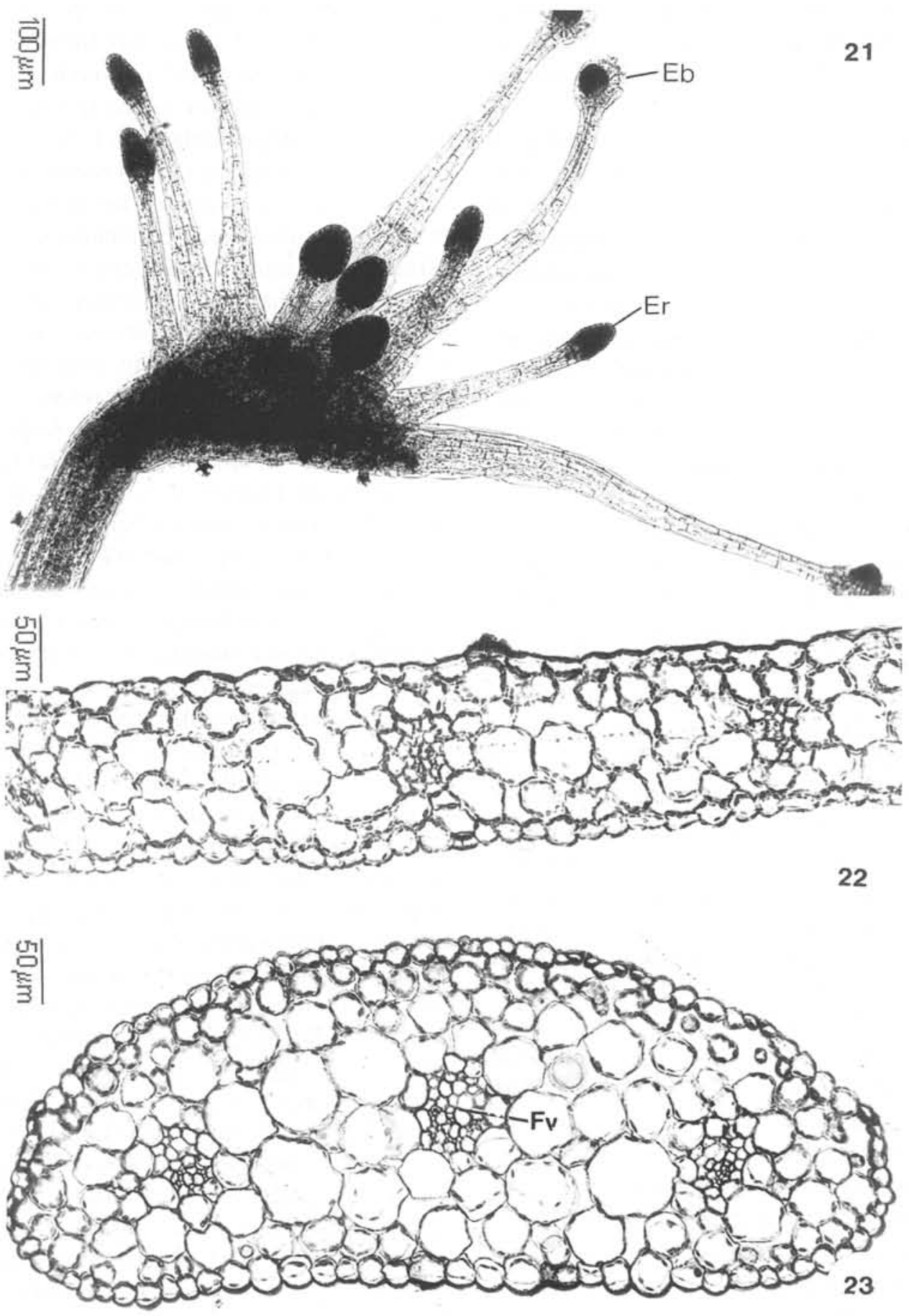

Figura 21. Folha de plântula de D. burmanni. Fig. 22-23. Corte transversal da lâmina e pecíolo de folha adulta, respectivamente, de $D$. intermedia. Eb-emergência bilateralmente simétrica; Er-emergência radialmente simétrica; Fvfeixe vascular. 

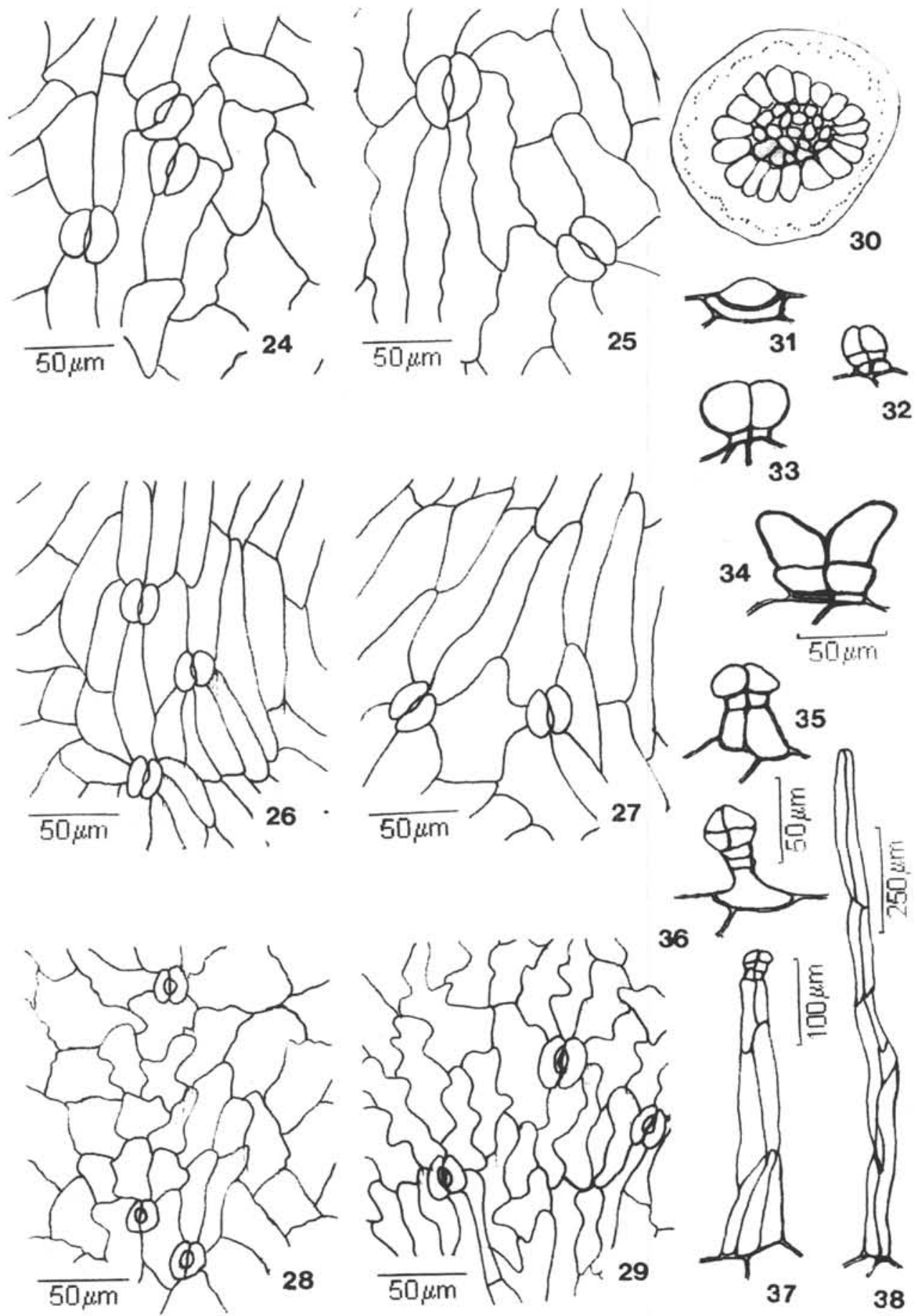

Figuras 24-29. Epiderme foliar em vista frontal. Fig. 24-25. D. spathulata. Fig. 26-27. D. intermedia. Fig. 28-29. D. burmanni. Fig. 24, 26, 28. Superfície adaxial. Fig. 25, 27, 29. Superfície abaxial. Fig. 30-38. Diferentes tipos de tricomas encontrados nos cotilédones, folhas e emergências das três espécies de Drosera (30 em visão superior; 31-38 em visão lateral). 
da Fig. 33 também estejam presentes nos pecíolos. Em D. spathulata são mais freqüentes os tricomas da Fig. 34, mas nos pecíolos ocorrem também os da Fig. 38. Nas lâminas e pecíolos de $D$. burmanni, encontram-se os tricomas da Fig. 36 e aqueles da Fig. 37 restringem-se às emergências e à superfície foliar adaxial; nesta última espécie ocorrem, ainda, tricomas como os da Fig. 33, nos pecíolos, e como os da Fig. 30, na superfície adaxial da lâmina.

Para Juniper et al. (1989), os tricomas glandulares de Drosera não possuem função definida ou estão envolvidos no transporte de fluido digestivo. Para Seine \& Barthlott (1993), eles constituem formas primitivas de glândula digestiva. Entretanto, como na secreção das emergências ocorrem mucilagem e enzimas, eficientes no aprisionamento e digestão dos artrópodos (Juniper et al. 1989), a presença de outras glândulas digestivas parece ser desnecessária. Além do mais, para que uma presa fosse atingida pelo material secretado por pequenos tricomas isolados, seria necessário que ela entrasse em contato direto com a superfície das emergências e/ou do limbo foliar. $\mathrm{O}$ fato desses tricomas estarem presentes nos cotilédones, estruturas não especializadas na captura de insetos, pode sugerir que eles não tenham ação digestiva. Talvez estejam relacionados à secreção de substâncias voláteis, que auxiliariam na atração dos insetos. Entretanto, somente estudos bioquímicos podem confirmar essa suposição.

\section{Referências bibliográficas}

Andrade-Lima, D. \& Lima, A. M. B. 1968. Flora de Pernambuco - Angiospermae II. In: Anais do XIX Congresso Nacional de Botânica.

Barroso, G. M. 1978. Família Droseraceae. Pp.170-171. In: Sistemática de Angiospermas do Brasil. LTC/ EDUSP, Rio de Janeiro.

Boesewinkel, F. D. 1989. Ovule and seed development in Droseraceae. Acta Botanica Neerlandica 38: 295-311.

Conran, J. G.; Jaudzems, V. G. \& Hallam, N. D. 1997. Droseraceae germination patterns and their taxonomic significance. Botanical Journal of the Linnean Society 123: 211-223.
Cook, C. D. K. 1987. Dispersion in aquatic and amphibious vascular plants. Pp.179-192. In: R. M. M. Crawford (Ed.), Plant life in aquatic and amphibious habits. Blackwell Scientific Publication, Oxford.

Cronquist, A. 1981. An integrated system of classification of flowering plants. Pp.374-376. Columbia University Press, New York.

Cutter, E. G. 1986. Anatomia vegetal. Parte I - Células e Tecidos. Livraria Rocca Ltda, São Paulo.

Darwin, C. R. 1896. Insectivorous Plants. D. Appleton and Company, New York.

Diels, L. 1906. Drosera. Pp.61-128. In: Engler, A. Das Pflanzenreich. Wilhelm Engelmann, Leipzig.

Fahn, A. 1978. Anatomia Vegetal. Selecciones Gráficas, Madrid.

Fernandes, A. 1941. Morfologia e biologia de plantas carnívoras. Anuário da Sociedade Broteriana 7: 16-52.

Johansen, D. A. 1940. Plant microtechnique. McGraw-Hill Bood Co., New York.

Juniper, B. E.; Robins, R. J. \& Joel, D. M. 1989. The carnivorous plants. Academic Press, Oxford.

Leavitt, R. G. 1903. Reversionary stages experimentally induced in Drosera intermedia. Rhodora 5: 265272.

Leavitt, R. G. 1909. Seedlings and adventitious plants of Drosera. Torreya 9: 200-203.

Lloyd, F. E. 1942. The carnivorous plants. The Ronald Press Company, New York.

O'Brien, T. P.; Feder, N. \& McCully, M. E. 1964. Polychromatic staining of plant cell walls by toluidine blue O. Protoplasma 59(2): 368-373.

Raven, P. H.; Evert, R. F. \& Eichhorn, S. E. 1996. Biologia vegetal. Editora Guanabara Koogan S.A., Rio de Janeiro,

Ruetze, M. \& Schmitt, V. 1986. Glykol-methacrylat (GMA) als Einbettungssystem is hislogische Untersuchungen von Koniferen - Nadein. European Journal of Plant Pathology 16: 321324.

Saint-Hilaire, A. 1824a. Drosera communis. Plantes Usuelles des Brasiliens 1(3): 1-4. Grimbert, Paris.

Saint-Hilaire, A. 1824b. Droseraceae. Histoire des plantes les plus remarquables du Brésil et du Paraguay 1: 253-271. A. Berlin, Paris.

Santos, E. 1968. Droseraceae do Rio de Janeiro. Boletim do Museu Nacional, Botânica 35: 1-9.

Santos, E. 1980. Droseráceas. In: Reitz, R. (Ed.). Flora Ilustrada Catarinense. 
Sculthorpe, D. 1967. The biology of aquatic vascular plants. Edward Arnold Publishers Ltd., London. Seine, R. \& Barthlott, W. 1993. On the morphology of trichomes and tentacles of Droseraceae Salisb. Beitraege zur Biologie der Pflanzen 67: 345 366.

Silva, T. R. S. 1991. Droseraceae. Pp. In: Barros et al. (Ed.), Caracterização geral da vegetação e listagem das espécies ocorrentes. Flora da Ilha do Cardoso 1: 95 .

Silva, T. R. S. 1994. Estudos taxonômicos de Drosera L. (Droseraceae) do Brasil. Dissertação de Mestrado. Universidade de São Paulo, São Paulo.

Silva, T. R. S. 1995. Droseraceae. In: Rizzo (Ed), Flora dos Estados de Goiás e Tocantins 18.
Theobald, W. L.; Krahulik, J. L. \& Rollins, R. C. 1979. Trichome description and classification. Pp.40-53. In: C. R. Metcalfe \& L. Chalk (Eds.), Anatomy of Dicotyledons. Clarendon Press, Oxford.

Tillich, H. J. 1995. Seedlings and systematics in monocotyledons. In: P. J. Cribb, D. F. Cutler, C. J. Humphries (Eds.), Monocotyledons: systematics and evolution.

Williams, S. E.; Albert, V. A. \& Chase, M. W. 1994. Relationships of Droseraceae: a cladistic analysis of $r b c \mathrm{~L}$ sequence and morphological data. American Journal of Botany 81(8): 1027-1037. 